\title{
A JUSTIÇA SOCIAL POR MEIO DAS COTAS \\ NA UNIVERSIDADE FEDERAL DE RONDÔNIA
}

\author{
ZUIN, Aparecida Luzia Alzira (Brasil, Rondônia, Porto Velho) ${ }^{1 \times}$ \\ BASTOS, Eliane (Brasil, Rondônia, Porto Velho) ${ }^{1}$ \\ ${ }^{1}$ Universidade Federal de Rondônia \\ ORCID ID: https://orcid.org/0000-0002-5838-2123 \\ ORCID ID: https://orcid.org/0000-0001-8210-5874
}

\begin{abstract}
RESUMO
O problema que orientou esta pesquisa foi se a Lei n. 12.711/2012 (Lei de Cotas), como política pública de ação afirmativa, é favorável ao atendimento da justiça social. Para traçar o perfil dos estudantes que ingressaram na Universidade Federal de Rondônia por meio das cotas tomou como base documental os registros acadêmicos da instituição. O aporte teórico-epistemológico respaldou-se nas concepções de Paulo Freire em seu método dialético-crítico. Sobre a escolha dos cursos analisados, Medicina e Direito, levou-se em consideração a maior concorrência nos processos seletivos da Universidade Federal de Rondônia (2013-2018), apontando: Medicina em primeiro lugar e Direito em segundo; a sua tradição na formação da classe elitizada brasileira e o status que ambos os cursos pressupõem dar aos concluintes. Os resultados assinalaram que as cotas hoje, apesar de uma série de críticas, oposições e erros de aplicação, têm sido a possibilidade de ingresso no Ensino Superior público.
\end{abstract}

\section{PALAVRAS-CHAVE}

Lei de Cotas. Justiça social. Medicina. Direito. UNIR.

\section{SOCIAL JUSTICE BY MEANS OF QUOTAS} AT THE FEDERAL UNIVERSITY OF RONDÔNIA

\begin{abstract}
The problem that guided this research was whether Law No. 12.711/2012 (Law of Quotas), as a public policy of affirmative action, is favorable to social justice. In order to trace the profile of the students who joined the Federal University of Rondônia, through the quotas, it took as a documentary basis the academic records of the Institution. The epistemological theoretical support was based on the conceptions of Paulo Freire in his critical dialectical method. Regarding the choice of courses analyzed, Medicine and Law, it was taken into consideration the greater competition in the selective processes of Federal University of Rondônia (2013-2018), pointing out: Medicine, in the first place; Right, second; the tradition of these in the formation of the Brazilian elite class, the status that both courses presuppose to give the graduating class. The results pointed out that quotas today, despite a series of criticisms, oppositions and errors of application, have been the possibility of entering public higher education.
\end{abstract}

\section{KEYWORDS}

Law of Quotas. Social justice. Medicine. Right. UNIR. 


\title{
LA JUSTICIA SOCIAL POR MEDIO DE LAS CUOTAS EN LA UNIVERSIDAD FEDERAL DE RONDÔNIA
}

\begin{abstract}
RESUMEN
El problema que orientó esta investigación fue si la Ley n. 12.711/2012 (Ley de Cuotas), como política pública de acción afirmativa, es favorable a la atención de la justicia social. Para trazar el perfil de los estudiantes que ingresaron en la Universidad Federal de Rondônia a través de las cuotas tomó como base documental los registros académicos de la institución. El aporte teóricoepistemológico se respaldó en las concepciones de Paulo Freire en su método dialéctico crítico. En cuanto a la elección de los cursos analizados, Medicina y Derecho, se tuvo en cuenta la mayor competencia en los procesos selectivos de la Universidad Federal de Rondônia (2013-2018), apuntando: Medicina en primer lugar y Derecho en segundo lugar; la tradición de estos en la formación de la clase elitizada brasileña y el status que ambos cursos presuponen dar a los concluyentes. Los resultados señalaron que las cuotas hoy, a pesar de una serie de críticas, oposiciones y errores de aplicación, han sido la posibilidad de ingreso en la enseñanza superior pública.
\end{abstract}

\section{PALABRAS CLAVE}

Ley de Cuotas. Justicia social. Medicina. Derecho. UNIR.

\section{INTRODUÇÃO}

A negação ao acesso sistematizado do saber aos mais desfavorecidos é exercida de forma desigual desde o início do processo educativo brasileiro. O ingresso nas instituições de ensino superior dava-se por um processo meritocrático. Ingressavam nas universidades públicas aqueles que auferiam as maiores notas nos vestibulares, mecanismo que foi substituído por muitas instituições pelo resultado do Exame Nacional do Ensino Médio (ENEM). A meritocracia alcançada e defendida pela classe dominante, sob a óptica da globalização e do neoliberalismo, construiu um aparato ideológico no intuito de desvirtuar o verdadeiro significado de igualdade, justiça social e equidade. A isso se acrescenta a dificuldade do ingresso de cidadãos e cidadãs nas instituições públicas de ensino com qualidade, quer sejam de nível fundamental e médio, quer sejam de ensino superior.

É a partir desse ponto de observação que a presente pesquisa se pauta, no sentido de analisar a aplicação da Lei n. 12.711/2012, comumente conhecida como a Lei de Cotas, na Universidade Federal de Rondônia (UNIR), como forma de ingresso dos alunos advindos de escolas públicas no ensino superior público. Para isso, apresenta os

Educação \& Formação, Fortaleza, v. 4, n. 12, p. 104-123 set./out. 2019

DOI: https://doi.org/10.25053/redufor.v4i12.945

http://seer.uece.br/redufor 
índices da desigualdade educacional entre alunos das escolas pública e privada, da cidade de Porto Velho, Rondônia, que ingressaram na UNIR nos cursos de Direito e Medicina no período de 2013 a 2018. Aborda a política pública de ação afirmativa como medida redutora dos graves problemas de desigualdades existentes na sociedade brasileira e consequentemente na educação. Com o objetivo de analisar a aplicação da Lei de Cotas nos cursos de Direito e Medicina da UNIR, propôs responder ao seguinte problema: as cotas, como política de ação afirmativa, têm conferido justiça social com equidade àqueles que delas necessitam para o ingresso no ensino superior? Com base nos dados estatísticos e fatos históricos, a pesquisa visa demonstrar que as cotas hoje, apesar de uma série de críticas, oposições e erros de aplicação, têm sido a possibilidade de ingresso no ensino superior público, principalmente nos cursos de graduação mais concorridos, para os estudantes pretos, pardos, indígenas e de baixa renda nessa instituição federal de ensino superior.

\section{O INGRESSO NO ENSINO SUPERIOR PÚBLICO E AS COTAS}

O processo histórico do Brasil, no que se refere à sua formação social, quanto à garantia de direitos, foi marcado por várias desigualdades geradas pela distribuição dessemelhante das riquezas. Apesar de ser um país com potencial crescimento econômico, ocupando, conforme anunciado pelos meios de comunicação, com base no relatório "Perspectivas para a economia global", do Fundo Monetário Internacional (FMI), em 2015, a oitava posição no ranking da economia no cenário mundial, ainda assim há grandes disparidades sociais.

No tocante à questão da discriminação, embora diga ser a nação das diversidades, o país ainda enfrenta desafios, principalmente em se tratando das causas dos direitos humanos e educacionais das populações indígenas e negras. Ambos os motivos estão atrelados ao modelo econômico capitalista vigente, que leva em conta muito mais o lucro advindo da produção que a distribuição da renda para quem produz, em termos de equidade.

Atualmente é possível observar que mudanças impulsionadas pelas legislações, mesmo que não na proporção que deveriam ocorrer, têm surgido na sociedade, com

Educação \& Formação, Fortaleza, v. 4, n. 12, p. 104-123 set./out. 2019

DOI: https://doi.org/10.25053/redufor.v4i12.945

http://seer.uece.br/redufor 
destaque aos grupos minoritários ${ }^{1}-$ negros e indígenas. Daí esta pesquisa compor 0 escopo dos estudos, visando entender como esses dois grupos passaram a ser atendidos por meio de políticas públicas do Governo Federal, mas também propondo compreender os movimentos sociais que se voltam à inclusão de negros e indígenas.

Dentre as políticas públicas educacionais há aquelas destinadas aos grupos minoritários, direcionadas ao acesso à educação, especificamente as ações afirmativas instituídas em reserva de vagas, as conhecidas cotas, materializada na Lei n. 12.711, de 29 de agosto de 2012. Nessa perspectiva, grande parte das instituições públicas de ensino, incluindo as federais, adotam as cotas como política de ação afirmativa com o objetivo de ampliar o acesso às suas vagas para as pessoas que fazem parte de grupos minoritários, vinculando ou não cota social e/ou cota racial. Ou seja, é possível as instituições de ensino utilizarem as cotas rígidas, quando utilizam apenas um critério, ou as cotas flexíveis, quando vinculam mais critérios, como raça/etnia e classe social.

Essa política, apesar das críticas e pontos falhos, é realidade até o momento, embora possa ser revogada a qualquer tempo em decorrência da alternância do Governo Federal (2019), precisando ser respeitada, pois a diversidade é educativa e conviver com diferentes é parte integrante de uma educação inclusiva para o século XXI. Dessa forma, a pesquisa teve como propósito apresentar se a situação real do processo de inclusão, por meio da Lei n. 12.711/2012, é de fato condizente com a realidade dos negros e indígenas, conferindo sua plena efetividade, o acesso à justiça e o ingresso dos negros e indígenas nos cursos de maior concorrência - Medicina e Direito - da UNIR.

\section{AS COTAS NA UNIR NOS CURSOS DE MEDICINA E DIREITO}

A principal regra quando se aplica a Lei n. 12.711/2012 é justamente a "origem escolar" da pessoa que está concorrendo a uma vaga nas cotas. É necessário que o educando tenha estudado integralmente o ensino médio em escolas públicas. Essa regra está pautada justamente no fato de que os alunos de escolas particulares têm uma qualidade melhor de ensino, uma vez que normalmente são preparados desde cedo para

\footnotetext{
1 O termo "minoria" utilizado neste artigo relaciona-se ao sentido antropológico, e não numérico, ou seja, consideram-se minorias os grupos sociais historicamente excluídos, que não têm a mesma situação de igualdade do grupo dominante.
}

Educação \& Formação, Fortaleza, v. 4, n. 12, p. 104-123 set./out. 2019

DOI: https://doi.org/10.25053/redufor.v4i12.945 
o vestibular e o ENEM. Dentro de um processo meritocrático de ingresso no ensino superior público, os discentes de escolas públicas, em uma óbvia desvantagem, teriam dificuldade de ingressar.

Para ilustrar a questão, apresentamos alguns gráficos da ampla concorrência dos cursos de Direito e Medicina da UNIR. Na ampla concorrência, que é um percentual a ser preenchido por candidatos que não se enquadram nas vagas das ações afirmativas, as vagas são ocupadas pelos alunos que obtiveram as maiores notas no ENEM. O Gráfico 1 dá uma clara ideia do que acontece nas vagas destinadas à ampla concorrência. Ao analisarmos o ano de 2017, reforçamos a conclusão de que as vagas da ampla concorrência foram ocupadas majoritariamente por estudantes de escolas privadas de ensino.

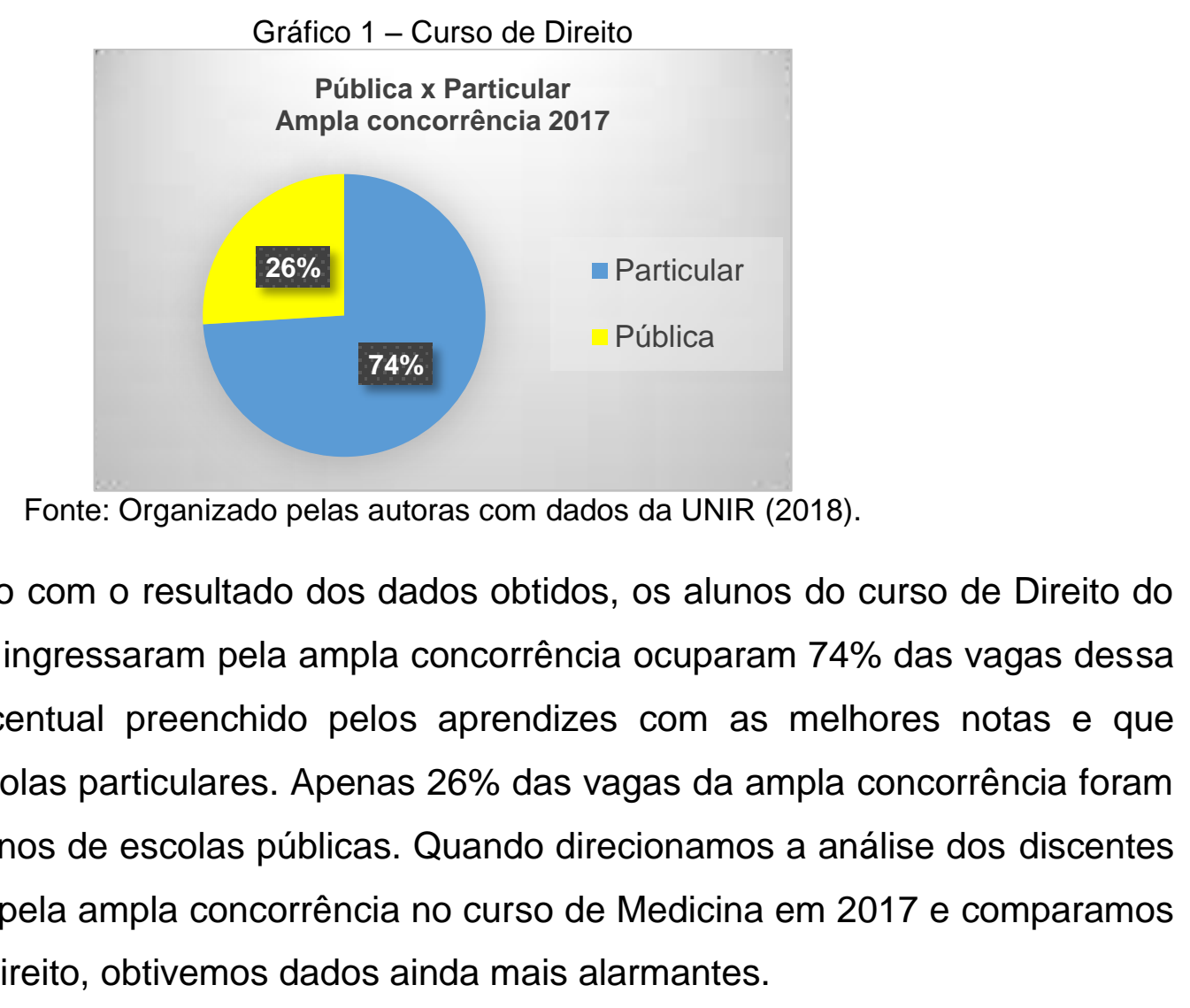

De acordo com o resultado dos dados obtidos, os alunos do curso de Direito do ano de 2017 que ingressaram pela ampla concorrência ocuparam 74\% das vagas dessa modalidade, percentual preenchido pelos aprendizes com as melhores notas e que frequentaram escolas particulares. Apenas $26 \%$ das vagas da ampla concorrência foram ocupadas por alunos de escolas públicas. Quando direcionamos a análise dos discentes que ingressaram pela ampla concorrência no curso de Medicina em 2017 e comparamos com o curso de Direito, obtivemos dados ainda mais alarmantes. 
Gráfico 2 - Curso de Medicina

Pública x Particular Ampla concorência 2017

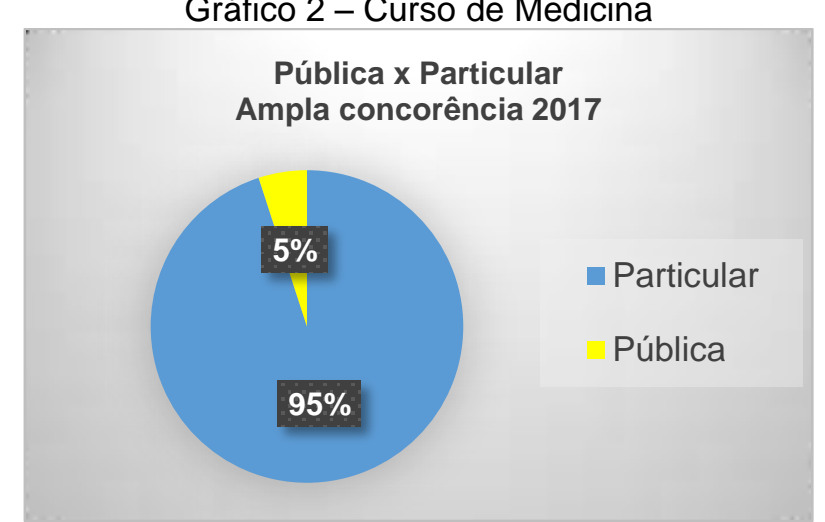

Fonte: Organizado pelas autoras com dados da UNIR (2018).

Dos 20 alunos matriculados na ampla concorrência, 95\% deles eram de escolas particulares, sendo apenas $5 \%$ oriundos de escolas públicas. Se o sistema de ingresso da UNIR fosse única e exclusivamente meritocrático (maior nota), possivelmente teríamos nos cursos de Direito e Medicina as vagas quase todas ocupadas por alunos de escolas privadas. Isso estaria condizente com a afirmação de Bertúlio (2012, p. 50): "Universidade brasileira sempre foi um espaço de méritos, que era ocupado exclusivamente pela elite intelectual do país".

Paulo Freire (2014) adverte que sociedades como a brasileira geram ideologias em que a culpa pelo fracasso e insucesso das pessoas é do próprio indivíduo; fracassado como profissional, fracassado como estudante. A culpa nunca é da estrutura e de como a sociedade funciona.

Se os garotos negros não aprendem bem o inglês, a culpa é deles, de sua incompetência 'genética', e não da discriminação a que são submetidos, de raça e de classe [...]. É o mesmo que ocorre no Brasil. Os meninos e as meninas dos morros e dos córregos não aprendem porque são, de nascença, incompetentes. (FREIRE, 2014, p. 216).

Essa estrutura social que Paulo Freire (2014) aborda pode ser facilmente observada na universidade quando analisamos o Gráfico 3. Ao compararmos a origem escolar (onde cursaram o ensino médio) dos alunos ingressantes nos anos de $2013 \mathrm{e}$ 2017, avistamos nitidamente as transformações que as cotas provocaram no perfil dos acadêmicos. No ano de 2013, quando a UNIR aplicou a reserva de vagas para as cotas em um percentual de $12,5 \%$, as vagas oferecidas eram ocupadas na maioria por discentes de escolas particulares. 
Gráfico 3 - Origem escolar - Direito 2013

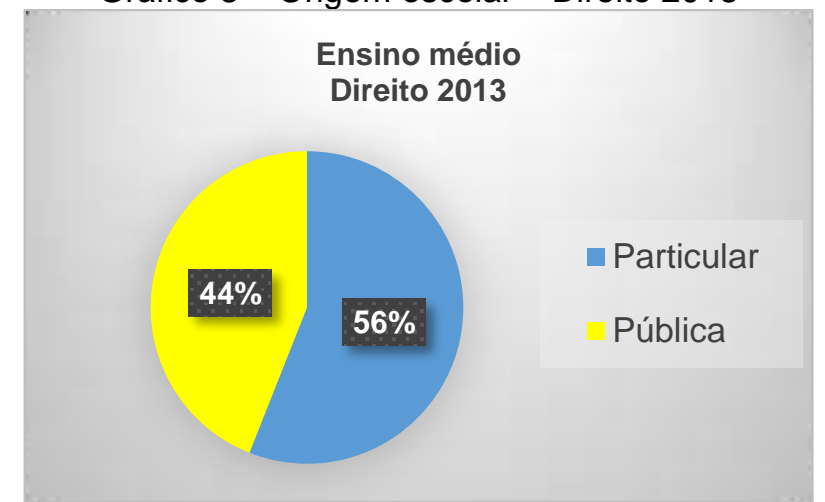

Fonte: Organizado pelas autoras com dados da UNIR (2018).

O curso de Direito em 2013 era formado por 44\% de estudantes de escolas públicas e 56\% de educandos oriundos de instituições privadas de ensino. Em 2017, com a aplicação de $50 \%$ de reserva de vagas para cotistas, este quadro sofreu uma grande transformação. No Gráfico 4, podemos constatar claramente que o número de vagas ocupadas por alunos de escola pública passou a superar o número de vagas destinadas a aprendizes de escolas privadas.

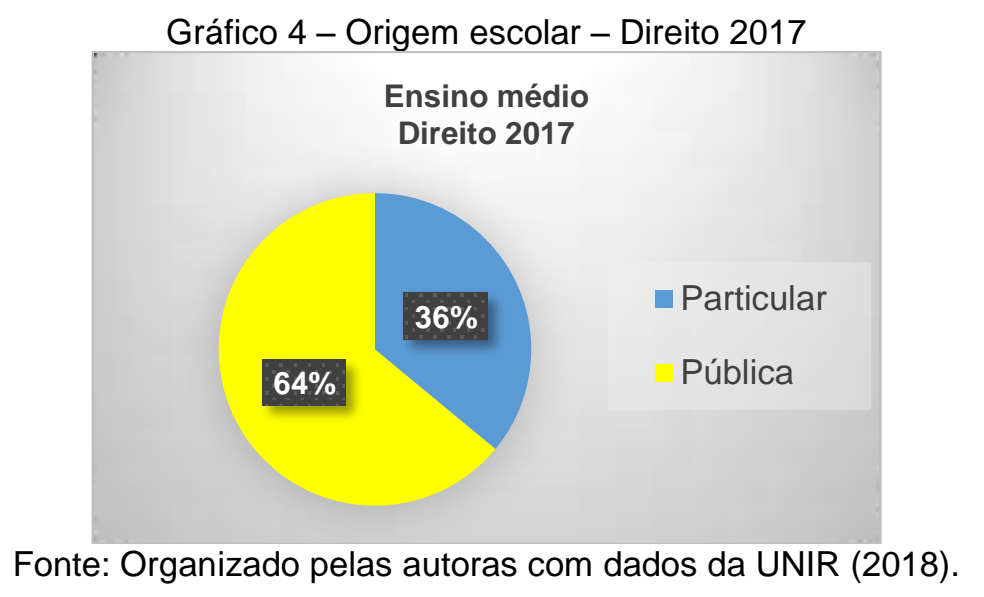

Dos 50 alunos matriculados no curso de Direito em 2017, 36\% eram de escolas privadas e $64 \%$ eram de escolas públicas de ensino. Nos resultados encontrados com os ingressantes no curso de Medicina nos mesmos períodos, verificamos que os números foram ainda mais significativos.

A aplicação das cotas mudou o quadro quando determinou que $50 \%$ das vagas de cada curso devessem ser destinadas aos discentes que cursaram o ensino médio, em todas as séries, em escolas públicas. Pode-se comprovar que as políticas públicas de ações afirmativas aplicadas para o acesso à educação superior garantem o equilíbrio 
das vagas, contribuindo para o alcance da justiça e equidade para o ingresso no ensino superior público.

$\mathrm{Na}$ análise do ingresso dos alunos em 2013 (Gráfico 5), quando o curso de Medicina aplicava $12,5 \%$ para as cotas, comparada com a referente a 2017 , em que a instituição passou a aplicar os 50\% previstos em lei, é possível reconhecer a mudança no perfil dos alunos ingressantes com maior representatividade da escola pública.

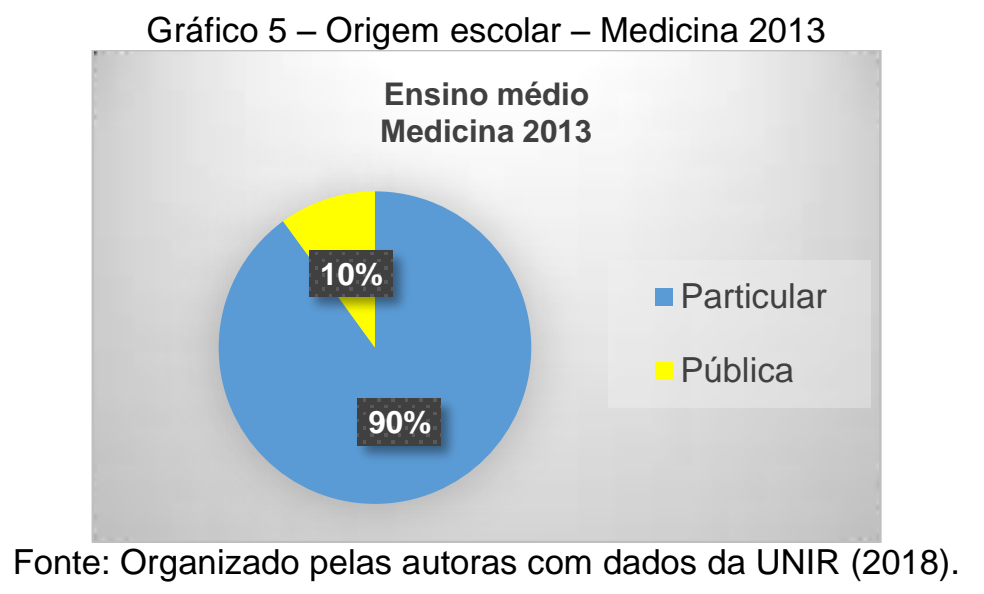

Em 2013, dos 40 estudantes matriculados no curso de Medicina, 90\% eram de escolas particulares e apenas $10 \%$ eram de escolas públicas de ensino. Exatamente como observou Gomes (2005): antes das cotas, os educandos das universidades brasileiras eram na maioria advindos do sistema privado de ensino. Ao investigarmos esses mesmos dados no ano de 2017, houve uma expressiva mudança no perfil dos alunos ingressantes no curso. Os resultados apresentados no Gráfico 6 comprovam a hegemonia da elite estudantil das escolas privadas quebrada com a aplicação das cotas nas universidades públicas.

Gráfico 6 - Origem escolar - Medicina 2017



Fonte: Organizado pelas autoras com dados da UNIR (2018).

Educação \& Formação, Fortaleza, v. 4, n. 12, p. 104-123 set./out. 2019 
O equilíbrio proporcionado pelas cotas é evidenciado através do curso de Medicina; em 2017, passou para $48 \%$ dos seus matriculados advindos de escolas privadas de ensino e $52 \%$ de escolas públicas. A representatividade social passa a ser correspondente àquela que há nos estratos existentes na sociedade brasileira, agora, sim, de acordo com o percentual desses grupos em cada região.

Ao compararmos as entradas dos aprovados de 2013 e 2017 do curso de Medicina, podemos entender melhor como a Lei n. 12.711/2012 tem sido usada para trazer equilíbrio ao desequilíbrio educacional no país. A educação para a justiça social é aquela que se abre para os excluídos e menos favorecidos. É aquela que dá vez às minorias e oferece oportunidade aos marginalizados. Trazer esses grupos para dentro do universo acadêmico sempre foi o objetivo de muitos educadores, como diria Paulo Freire (2014, p. 62), "[...] sonhos são projetos pelos quais se luta”. Uma luta que levou 33 anos dentro do Congresso Nacional brasileiro. De 1980, ano da primeira proposta de ação afirmativa, a 2013, com a aplicação real da lei que obrigou a reserva de vagas nas instituições públicas de ensino superior para estudantes negros, indígenas, deficientes e de baixa renda, os embates foram muitos. Não diferente foi para a aplicação da Lei de Cotas na UNIR.

O Gráfico 7, que ilustra a renda familiar dos alunos do curso de Direito, dá uma clara ideia do que as cotas representam dentro das universidades, sobretudo em cursos elitizados como os Direito e Medicina.

\section{Gráfico 7 - Média da renda familiar - Direito}

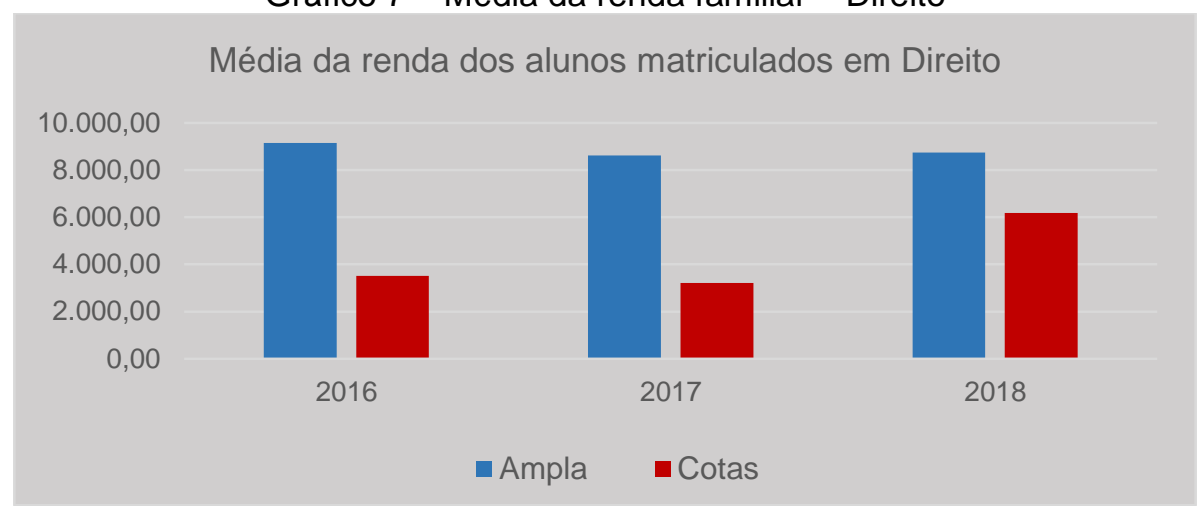

Fonte: Organizado pelas autoras com dados da UNIR (2018).

Aqui a média da renda familiar dos alunos do curso de Direito matriculados na ampla concorrência não é tão acentuada como a observada no Gráfico 8 , que demonstra

Educação \& Formação, Fortaleza, v. 4, n. 12, p. 104-123 set./out. 2019 
a renda familiar dos ingressantes na ampla concorrência muito maior comparada com os ingressantes pela cota social.

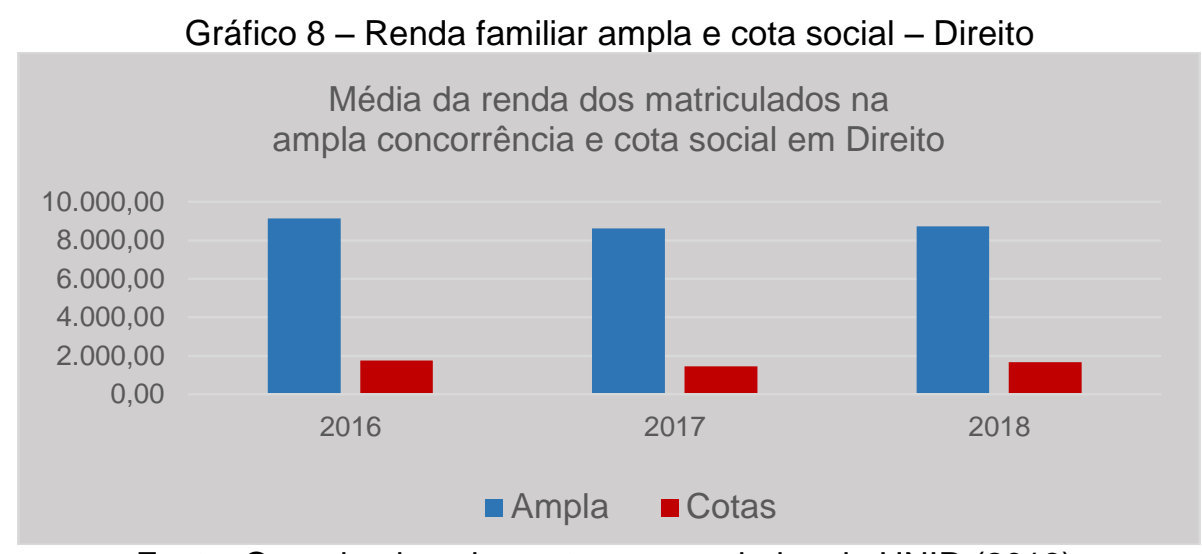

Fonte: Organizado pelas autoras com dados da UNIR (2018).

O fator média da renda familiar no curso de Medicina identifica que, apesar de os dados se alterarem em determinados momentos, o mesmo fenômeno do curso de Direito também ocorre na Medicina.

Gráfico 9 - Média da renda familiar - Medicina



Fonte: Organizado pelas autoras com dados da UNIR (2018).

O curso de Medicina, quando comparado com o de Direito, tanto na ampla concorrência quanto nas cotas, apresenta as maiores médias de renda familiar, todavia, quando comparados entre si com relação aos aspectos de ampla concorrência e cotas, notamos que, neste caso, também a diferença entre as duas modalidades é bastante significativa. Essa diferença torna-se ainda maior quando retiramos do cálculo os educandos que foram matriculados nas cotas, independentemente da renda, e mantendo apenas os da cota social, conforme demonstra o Gráfico 10:

Educação \& Formação, Fortaleza, v. 4, n. 12, p. 104-123 set./out. 2019 


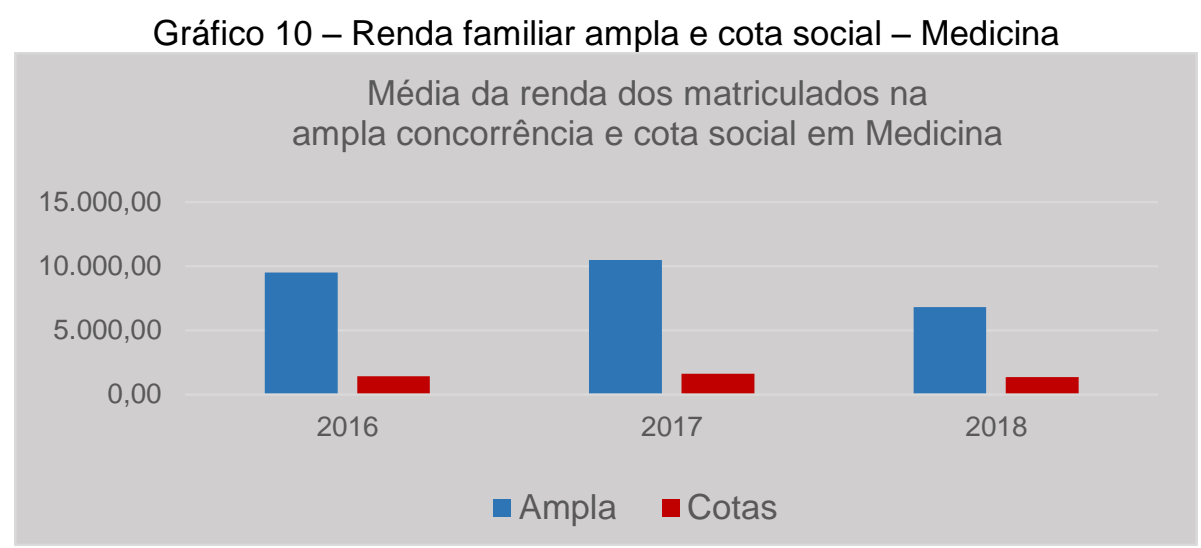

Fonte: Organizado pelas autoras com dados da UNIR (2018).

Os resultados dos dados do curso de Medicina da UNIR, assim como os dados do curso de Direito, apresentam uma relevante diferença entre a média de renda da ampla concorrência e da cota social. Ao subtrairmos os alunos matriculados nas cotas, independentemente de renda do cálculo das médias, verificamos que as diferenças socioeconômicas se tornam ainda maiores entre as duas modalidades de ingresso.

Elaborar e concretizar políticas públicas para o acesso dos estudantes de baixa renda ao ensino superior é promover justiça social com equidade. Autores como Brandão (2005) e Kaufmann (2011) criticam as ações afirmativas por criarem privilégios a determinados grupos, uma vez que a Constituição de 1988 estabelece que todos somos iguais. Por sua vez, Piovesan (2012) lembra que a segregação ocorre quando, em situações diferentes, somos tratados iguais e, em situações iguais, somos tratados diferentes. Uma boa parcela da sociedade brasileira ainda nega a existência desses males, sobretudo na universidade pública brasileira. Nesse diapasão, analisamos a aplicação das ações afirmativas na UNIR dentro do critério "cor/raça/etnia".

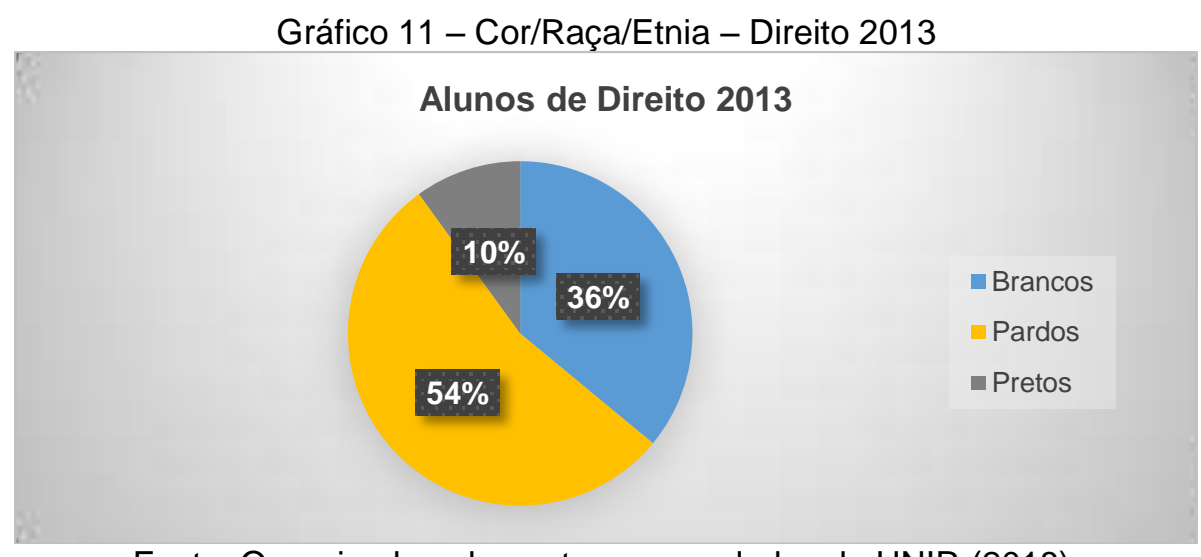

Fonte: Organizado pelas autoras com dados da UNIR (2018).

Educação \& Formação, Fortaleza, v. 4, n. 12, p. 104-123 set./out. 2019 
O Gráfico 11 demonstra como era composto o curso de Direito em 2013, primeiro ano de aplicação das cotas na UNIR. Notamos que o curso era formado basicamente por três cores, distribuídos em: $54 \%$ dos matriculados pardos, $36 \%$ brancos e $10 \%$ pretos. Observamos que o curso não teve naquele ano nenhum indígena matriculado. No ano de 2013, a UNIR aplicou o percentual de $12,5 \%$ de vagas reservadas para cotas. Ao compararmos 2013 com o ano de 2017, em que a UNIR aplicou o percentual mínimo de $50 \%$ da reserva de vagas para cotas, ocorreu uma importante mudança no perfil "cor/raça/etnia" dos acadêmicos.

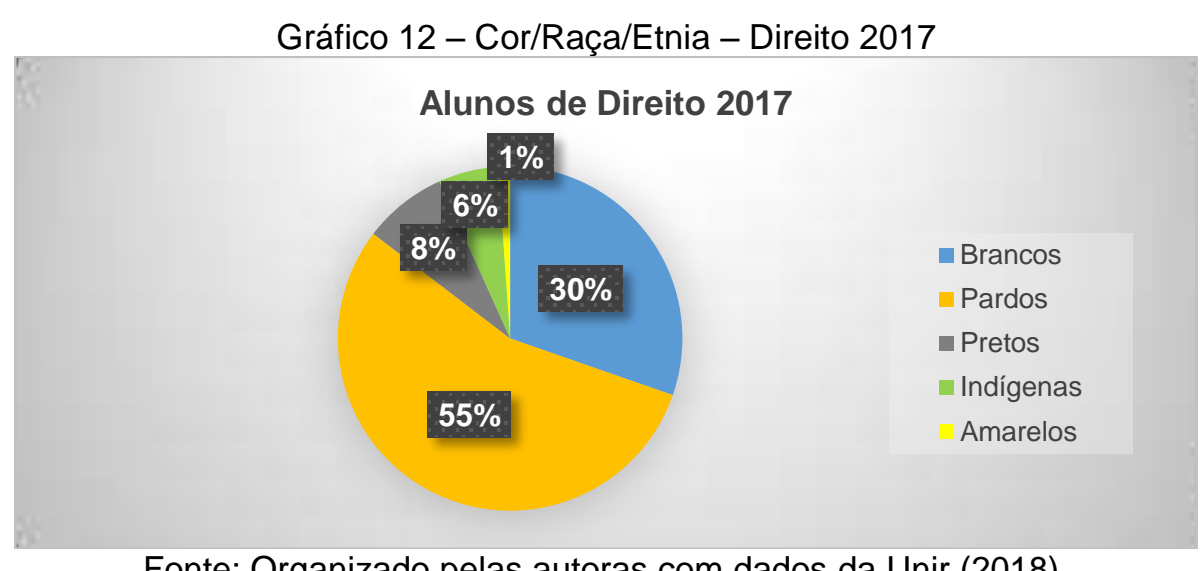

Fonte: Organizado pelas autoras com dados da Unir (2018).

A diversidade passou a ser proporcionada por meio das cotas. O curso de Direito, até então formado por pardos, brancos e pretos, passou a se compor, em 2017, de $55 \%$ de pardos, $30 \%$ de brancos, $8 \%$ de pretos, $6 \%$ de indígenas e $1 \%$ de amarelos. Os resultados dos dados do curso de Direito são inegáveis no quesito transformação do perfil "cor/raça/etnia" dos estudantes ingressantes.

Santos (2005, p. 16) aborda que o "[...] racismo contra os negros já não é mais negado pela maioria da população brasileira, embora seja ainda difícil encontrar brasileiros que admitam que eles mesmos discriminam os negros". As universidades brasileiras, apesar de não negarem a existência do racismo, promoviam, mesmo que veladamente, formas de racismo, discriminação e exclusão. Tomemos como referência para essa afirmativa os dois últimos gráficos apresentados acima, que retratam a realidade da UNIR, que nunca se preocupou em fazer estudos e levantamentos para saber a cor, a raça ou a etnia de seus estudantes; uma forma de se eximir da responsabilidade de praticar ações para reverter esse quadro. 
Quando voltamos para os resultados do curso de Medicina da UNIR, verificamos que essas diferenças são ainda maiores e extremamente relevantes. $O$ curso de Medicina, há tempos, foi ocupado pela elite brasileira, pode-se ainda dizer que é um curso majoritariamente de "brancos". Na UNIR esse quadro não era diferente. O gráfico adiante reforça essa afirmação.

Gráfico 13 - Cor/Raça/Etnia - Medicina 2013

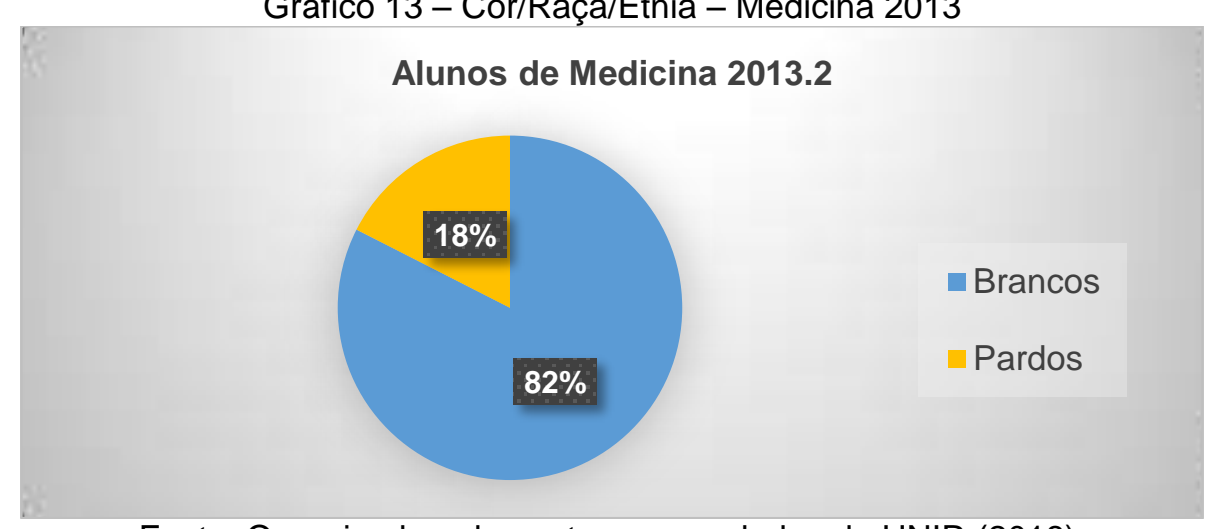

Fonte: Organizado pelas autoras com dados da UNIR (2018).

Em 2013, o curso de Medicina da UNIR era formado por $82 \%$ de discentes brancos e apenas $18 \%$ de pardos. As vagas do curso eram ocupadas exclusivamente por pessoas brancas. Ristoff (2014, p. 730) ressalta que o "Campus Universitário Brasileiro é $20 \%$ mais branco que a sociedade brasileira". O autor, ao falar sobre a cor das universidades, destaca que "[...] o campus é um espelho que distorce a imagem da sociedade ou, dito de outra forma, o campus, como um agente social ativo, aguça as distorções existentes na sociedade", pois a sociedade brasileira, de maioria parda e negra, visivelmente não estava até 2013 representada nas universidades, da mesma maneira que também não se encontrava representada na UNIR, como demonstra o gráfico acima.

Destacamos que o resultado dos dados de Medicina nos remete às questões do preconceito e do racismo existentes na sociedade brasileira, que são refletidos no âmbito acadêmico, espaço que não era destinado aos pretos, pardos e indígenas. Com a gradativa implementação das ações afirmativas na UNIR, aos poucos essa realidade se modificou. Os resultados dos dados "cor/raça/etnia" do curso de Medicina do ano de 2017 constatam essa transformação social.

Educação \& Formação, Fortaleza, v. 4, n. 12, p. 104-123 set./out. 2019 
Gráfico 14 - Cor/Raça/Etnia - Medicina 2017

Alunos de Medicina 2017.2

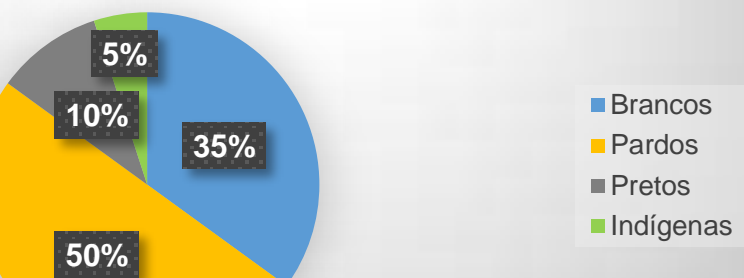

Fonte: Organizado pelas autoras com dados da UNIR (2018).

As mudanças ocorridas no curso de Medicina, ao longo dos últimos seis anos de implementação da Lei de Cotas, alteraram, inclusive, o perfil da instituição. Em 2017, o curso passou a ser formado por $50 \%$ de pardos, $35 \%$ de brancos, $10 \%$ de negros e $5 \%$ de indígenas, refletindo pela primeira vez o perfil da sociedade brasileira e principalmente o perfil da sociedade rondoniense, em que pretos e pardos somam $62,5 \%$ da população (IBGE, 2010). Nessa direção, diversidade e representatividade são dois pontos os quais a UNIR passou a conferir como instituição pública de ensino superior, haja vista que no curso de Direito os resultados não foram diferentes, conforme conferidos no Gráfico 15.

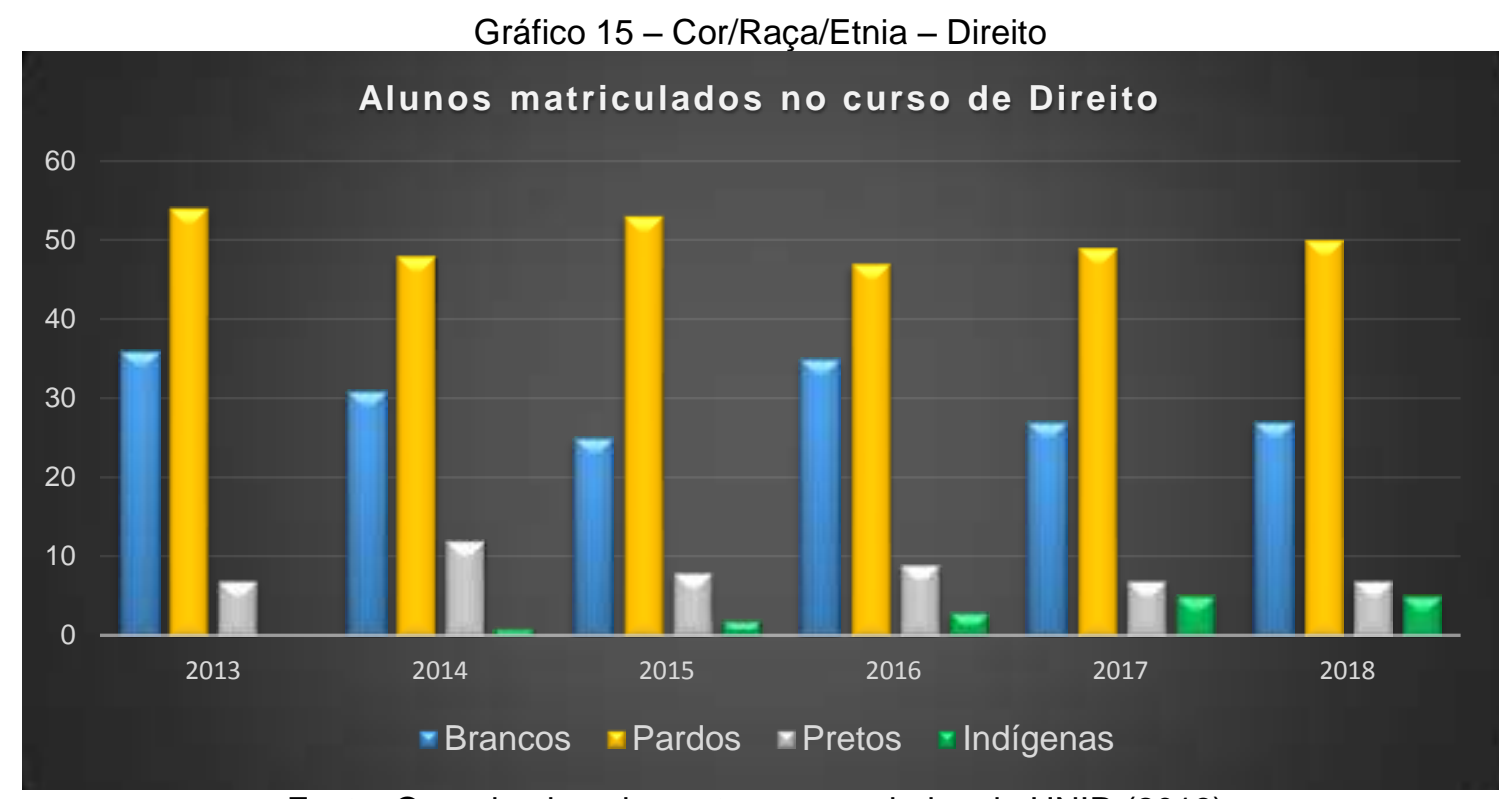

Fonte: Organizado pelas autoras com dados da UNIR (2018).

Educação \& Formação, Fortaleza, v. 4, n. 12, p. 104-123 set./out. 2019

DOI: https://doi.org/10.25053/redufor.v4i12.945

http://seer.uece.br/redufor 
Diversidade e representatividade dos grupos minoritários são metas das ações afirmativas que foram alcançadas com a implementação das cotas na UNIR. No Gráfico 15, de 2013 a 2018, no curso de Direito da UNIR, constatamos um terceiro grupo que nos anos anteriores sequer aparecia antes da Lei de Cotas: os indígenas.

Desde a promulgação da Constituição de 1988, que retirou a tutela do Estado sobre os indígenas, reconhecendo-lhes a capacidade civil, em um processo de autonomia desses povos, a educação do índio com relação à educação superior esteve pautada na formação de professores indígenas para atuarem nas aldeias. As cotas nas universidades trouxeram aos indígenas nova possibilidade e a oportunidade de escolherem entre os mais diversos cursos de graduação. No caso em questão do curso de Direito, comprovamos que a implementação das cotas propiciou o ingresso dos indígenas no ensino superior e também mudou o perfil do curso no quesito cor/raça/etnia proposto pelas cotas.

No tocante a essa temática, Gomes (2007, p. 52) lembra que "[...] é preciso uma ampla conscientização sobre o fato de que a marginalização socioeconômica a que são relegadas as minorias, especialmente as raciais, resulta de um único fenômeno: a discriminação", por isso a implementação de políticas públicas de ação afirmativa nas universidades significou uma tomada de consciência da sociedade brasileira, do meio acadêmico e das lideranças políticas no sentido de reduzir as desigualdades sociais às quais sempre foram submetidas as minorias raciais. O reconhecimento da existência do racismo, do preconceito e da discriminação já é um importante passo na direção das mudanças. A criação e implementação de políticas públicas de ação afirmativa que garantam a possibilidade de acesso desses grupos é a correção, se ainda não total, em parte, afinal o tempo de exclusão e segregação a que foram submetidos é de longo período histórico.

Diante disso, cabe o questionamento: o que a universidade pública tem feito para reverter esse quadro? Freire (2014, p. 77) afirma que, se a educação não pode fazer essa transformação, "[...] sem ela tampouco a sociedade muda". Após seis anos de ingresso dos primeiros estudantes cotistas na UNIR, os resultados levantados podem comprovar que as cotas, até o momento, são necessárias.

A melhor forma de as instituições públicas de ensino superior fazerem justiça social com equidade no ingresso dos alunos é exatamente por meio da aplicação das 
ações afirmativas nas universidades, ou seja, mediante a reserva de vagas, cotas para os mais fragilizados física, econômica e socialmente. É preciso entender que a aplicação da Lei de Cotas não acentua a discriminação, pelo contrário, tende a corrigir o problema da discriminação social, tão enraizada na sociedade brasileira desde sua formação. Nesse sentido, Ikawa (2008, p. 938) aponta que as ações afirmativas aplicadas nas universidades têm por objetivo não apenas combater as velhas formas de discriminação assentadas na sociedade brasileira, mas evitar novas formas de discriminação:

[...] se quaisquer considerações de vulnerabilidades específicas, como a discriminação racial, forem vistas como formas de acentuar as mesmas vulnerabilidades, nenhuma medida material poderá ser aceita, preservando-se o status quo; e o status quo aqui se refere à consolidação de novas formas de discriminação, e não à mera continuidade de discriminações passadas que estariam a se desfazer no tempo.

Quando determinados grupos criticam a aplicação de cotas nas universidades, na verdade o que esses grupos pretendem é a manutenção e/ou a preservação do status quo, ou uma nova forma de status quo, ou que essas diferenças sejam mantidas também no âmbito acadêmico. Ikawa (2008, p. 128) argumenta que esse posicionamento está "[...] somado ao apego a privilégios e a hierarquias morais ou convencionais, mantidos pela história por séculos, de forma articulada ou mesmo inarticulada em favor de certos grupos", grupos esses que veem surgir, através das cotas no ensino superior público, um certo rompimento desse status quo.

Brito Filho (2016) aponta que a presença dos alunos cotistas nas universidades públicas impõe às instituições toda uma gama de transformações, porque precisam se adequar à realidade, por isso surgem os programas especiais de acompanhamento, nivelamentos dos discentes quando necessário, programas de bolsas e auxílios para permanência, dentre outros. Apesar de todos os problemas que a UNIR enfrentou ao longo dos seis anos de aplicação das cotas, não se pode negar os benefícios trazidos pela implementação dessa ação afirmativa para a instituição. Pinto (2004, p. 753) assegura que um novo perfil dos alunos é um ponto decididamente positivo para a universidade:

A introdução de quotas, em especial se adotada nos cursos mais concorridos, trará um novo perfil de aluno, que, se é carente em uma série de conteúdos cobrados no vestibular (e que geralmente são

Educação \& Formação, Fortaleza, v. 4, n. 12, p. 104-123 set./out. 2019

DOI: https://doi.org/10.25053/redufor.v4i12.945

http://seer.uece.br/redufor 
desconsiderados posteriormente nos cursos de graduação), é rico em outros, decorrentes de um maior reconhecimento do país real, aquele onde vive a maioria da população, o que trará um ganho de qualidade às instituições de educação superior, sem falar daqueles advindos de uma composição social mais diversificada.

Como bem coloca Ikawa (2008, p. 152), “[...] enquanto há indivíduos que não mais podem ser alcançados por políticas universalistas de base, mas que sofreram os efeitos, no que toca à educação, da insuficiência dessas políticas, são necessárias, por conseguinte, também políticas afirmativas". Dessa forma, as cotas, como política pública de ação afirmativa, é, nesse momento histórico em que vivemos, o caminho para a inclusão de pretos, pardos, indígenas e estudantes de baixa renda no ensino superior público.

\section{CONCLUSÃo}

Para a conclusão, partimos da propositura dos estudos, isto é, analisar se a aplicação da Lei de Cotas nos cursos de Direito e Medicina da UNIR, campus Porto Velho, como política de ação afirmativa, resultou em justiça social com equidade por meio da diversidade e da representatividade. Daí chegamos à primeira conclusão: os cursos mais concorridos, como Direito e Medicina, por muitos anos, tiveram as vagas ocupadas pela parcela seleta da sociedade brasileira. A forma de ingresso dos estudantes nas universidades (vestibular) se fundava no modelo meritocrático acadêmico, ou seja, apenas os candidatos com as melhores notas ingressavam em uma instituição pública de ensino superior. Essa forma de ingresso, que levava em consideração para a aprovação apenas as maiores notas, foi sobremodo alterada pela implementação da Lei n. 12.711/2012 (Lei de Cotas) nas universidades públicas. Com a implementação das cotas nas instituições públicas de ensino superior, estudantes pretos, pardos, indígenas e de baixa renda passaram a ter a oportunidade de ingresso através da modalidade de reserva de vagas - as cotas.

A política pública de ação afirmativa - Lei de Cotas - objetiva ainda remediar um passado histórico de discriminação, preconceito, desigualdade e exclusão das minorias. No caso das instituições públicas de ensino superior, um passado de exclusão dos

Educação \& Formação, Fortaleza, v. 4, n. 12, p. 104-123 set./out. 2019 
grupos mais vulneráveis e de negação do direito à formação superior dos pretos, povos indígenas e população de baixa renda.

Concluímos que as vagas ofertadas nos cursos de Medicina e de Direito da UNIR, antes das cotas, eram ocupadas, quase que integralmente, por alunos de escolas privadas. Destacamos que esse quadro começou a se alterar a partir da aplicação da Lei n. 12.711/2012, com o ingresso de discentes de escolas públicas, de maneira que se observa o equilíbrio no tocante às vagas ocupadas. Identificamos que, no curso de Direito, até o ano de 2014, só havia alunos brancos, pretos e pardos. No ano de 2017, já com a aplicação legal de $50 \%$ de reservas de vagas, verificamos que o curso passou a ter pessoas autodeclaradas brancas, pretas, pardas, amarelas e indígenas, com e sem deficiência. Ao analisarmos o curso de Medicina, conferimos que, em 2013, ano de início da aplicação da Lei de Cotas, entre os estudantes matriculados no curso, $82 \%$ eram brancos e apenas $18 \%$ eram pardos, não havendo pretos ou indígenas. Confirmamos que, com a implementação da política das cotas, mudou completamente o perfil dos educandos do curso, sendo que, em 2017, as vagas foram ocupadas por $50 \%$ de pardos, $35 \%$ de brancos, $10 \%$ de pretos e $5 \%$ de indígenas.

Desse modo, os resultados encontrados acenam que a UNIR, com a aplicação da Lei de Cotas, tem efetivado a educação como um direito fundamental, assim como tem, na medida do possível e das suas competências, desempenhado sua função social, com oferecimento de educação socialmente justa e com equidade, e, por conseguinte, utilizado a educação como instrumento de inclusão e diversidade cultural.

\section{REFERÊNCIAS}

BERTÚLIO, D. L. L. Racismo e desigualdade racial no Brasil. In: DUARTE, E. C. P. (Coord.). Cotas raciais no Ensino Superior: entre o jurídico e o político. Curitiba: Juruá, 2012. p. 27-56.

BRANDÃO, C. F. As cotas na universidade pública brasileira: será esse o caminho? Campinas: Autores Associados, 2005.

BRASIL. Constituição de 1988. Constituição da República Federativa do Brasil. Diário Oficial [da] República Federativa do Brasil, Poder Executivo, Brasília, DF, 5 out. 1988. 
BRASIL. Lei n. 12.711, de 29 de agosto de 2012. Dispõe sobre o ingresso nas universidades federais e nas instituições federais de ensino técnico de nível médio e dá outras providências. Diário Oficial [da] República Federativa do Brasil, Poder Executivo, Brasília, DF, 30 ago. 2012.

BRITO FILHO, J. C. M. Ações afirmativas. São Paulo: LTr, 2016.

FREIRE, P. Pedagogia da indignação: cartas pedagógicas e outros escritos. São Paulo: Paz e Terra, 2014.

GOMES, J. B. B. Ação afirmativa \& princípio constitucional da igualdade: o Direito como instrumento de transformação social. Rio de Janeiro: Renovar, 2007.

GOMES, N. L. Alguns termos e conceitos presentes no debate sobre relações raciais no Brasil: uma breve discussão. Brasília, DF: MEC, 2005.

IBGE - Instituto Brasileiro de Geografia e Estatística. População chega a 205,5 milhões, com menos brancos e mais pardos e pretos. Disponível em: <https://agenciadenoti cias.ibge.gov.br/agencia-noticias/2010-agencia-de-noticias/noticias/18282-pnad-c-mora dores.html>. Acesso em: 10 abr. 2018.

IKAWA, D. As ações afirmativas em universidades. Rio de Janeiro: Lumen Juris, 2008.

KAUFMANN, R. F. M. A desconstrução ao mito da raça e a inconstitucionalidade de cotas raciais no Brasil. Revista Direito Público, Brasília, DF, v. 8, n. 36, p. 18-54, 2011.

PINTO, J. M. R. O acesso à educação superior no Brasil. Educação \& Sociedade, Campinas, v. 25, n. 88, p. 727-756, 2004.

PIOVESAN, F. Ações afirmativas sob a perspectiva dos direitos humanos. In: DUARTE, E. C. P. (Coord.). Cotas raciais no ensino superior. Curitiba: Juruá, 2012. p. 15-26.

RISTOFF, D. I. O novo perfil do campus brasileiro: uma análise do perfil socioeconômico do estudante de graduação. Avaliação, Campinas, v. 19, p. 723-747, 2014.

SANTOS, S. A. (Org.). Ações afirmativas e combate ao racismo nas Américas. Brasília, DF: MEC: Unesco, 2005.

UNIR - Universidade Federal de Rondônia. Departamento de Ciências Jurídicas. Disponível em: <http://www.dcj.unir.br/pages/npj.php>. Acesso em: 12 abr. 2018.

UNIR - Universidade Federal de Rondônia. Departamento de Medicina. Disponível em: <http://www.depmed.unir.br/>. Acesso em: 10 jun. 2018.

UNIR - Universidade Federal de Rondônia. Diretoria de Controle e Registro Acadêmico. Disponível em: <http://www.processoseletivo.unir.br>. Acesso em: 23 jun. 2018.

Educação \& Formação, Fortaleza, v. 4, n. 12, p. 104-123 set./out. 2019

DOI: https://doi.org/10.25053/redufor.v4i12.945

http://seer.uece.br/redufor 
UNIR - Universidade Federal de Rondônia. Processo seletivo. Disponível em: <http://www.unir.br/>. Acesso em: 9 jun. 2018.

UNIR - Universidade Federal de Rondônia. Vestibular UNIR. Disponível em: <http://www.vestibular.unir.br/>. Acesso em: 23 maio 2018.

Aparecida Luzia Alzira Zuin (Brasil, Rondônia, Porto Velho) Universidade Federal de Rondônia (UNIR)

Doutora em Comunicação e Semiótica pela Pontifícia Universidade Católica de São Paulo (PUC/SP) e vice-coordenadora do mestrado em Educação da UNIR.

Lattes: <http://lattes.cnpq.br/1584841068017210>.

E-mail: <alazuin@gmail.com>.

\section{Eliane Bastos (Brasil, Rondônia, Porto Velho)}

Universidade Federal de Rondônia (UNIR)

Mestra em Educação e graduada em Sociologia pela UNIR.

Lattes: <http://lattes.cnpq.br/8564478336193137>.

E-mail: <liabastosunir@gmail.com>.

Recebido em 28 de janeiro de 2019.

Aceito em 11 de abril de 2019. 